\title{
Rio de Janeiro: Modernidade Global e Intensidade no Espetáculo Urbano do Século XXI
}

\author{
Pedro Cláudio Cunca Bocayuva \\ Doutor em Planejamento Urbano e Regional pela \\ Universidade Federal do Rio de Janeiro (UFRJ). \\ Professor do Núcleo de Estudos de Políticas Públicas em Direitos Humanos \\ da Universidade Federal do Rio de Janeiro (UFRJ). \\ Contato: cunca-bocayuva@nepp-dh.ufri.br
}

O objetivo deste artigo é argumentar em favor da necessidade da formulaçáo de uma nova metodologia para a leitura crítica da conjuntura internacional com foco nas dinâmicas espaciais, tendo em vista o momento atual de conformação de uma reestruturação urbana na cidade do Rio de Janeiro. Nele procuramos identificar as tendências características das açôes de grande impacto urbano, apoiadas em políticas governamentais orientadas por padróes hegemônicos no plano transnacional. A partir da sua projeção na dimensão da definição dos modos de produção do espaço, pela apropriação das condições de reprodução social sob a hegemonia do capital que busca sua conexão ao ciclo global. Nossa proposta é indicar elementos para a análise situacional do fenômeno urbano na atualidade a partir de pensar a cidade do Rio de Janeiro como fronteira da acumulação global enquanto uma consequência lógica do percurso desenvolvido pelas políticas governamentais locais desde meados dos anos 1990. A agenda dos grandes eventos acabou se impondo como parte de um conjunto de diretrizes de governo para a Cidade.

\section{O Novo Paradigma e sua Difusáo}

O lugar é maior e menor que o mundo, nosso olhar informado pela análise do momento atual do Rio de Janeiro deve levar em conta a rede real, virtual e metafórica presente na noção de globalização do fenômeno urbano. $\mathrm{Na}$ Cidade Maravilhosa se desdobra na semiótica criada pelo padrão de planejamento, do chamado City Marketing, inventando e copiando, o processo de mudança que ocorreu em outras cidades. Nas pegadas em que se destacaram Barcelona, passando por Xangai até Londres, vemos os grandes negócios e as iniciativas corporativas moldarem a imagem da cidade, por meio de transformaçóes do tipo "water front", na construção de viadutos, na ampliação do sistema metroviário, na construção de grandes torres e numa enorme gentrificação da paisagem (re)construída. Vemos no Rio de Janeiro a reafirmação do deslocamento geográfico dessa lógica de pós-modernização para lugares mais ao sul do planeta, como ocorreu na África do Sul, como ocorreu em Beijing. O que antes foi um movimento de aproximaçáo e conexáo com as redes transnacionais, que partiu da tentativa de se aproximar da lógica das chamadas cidades globais, 
acabou virando um fenômeno de proliferação de pacotes e modelos de economia urbana.

Vemos se implantar a lógica voltada para uma arquitetura de negócios e de mídia, que se liga de forma complexa com as outras camadas de interesses empresariais e blocos sociais locais. Os modos de governar as grandes cidades seguem uma espécie de bolsa de apostas para promover uma agenda de projetos e construçóes para eventos, em nome da criação da imagem, do fortalecimento da marca, da geração de negócios e da economia dos serviços, da comunicação, da informação e do turismo, que se ligam aos processos de mobilização e criação de objetos orientados para realizar os vários objetivos de rentabilidade do capital. A reprodução social de certo tipo de sociedade se espalha numa lógica labiríntica e circular de espelhamento, a partir da realização das formas extremas da

hipermodernidade.

O novo paradigma da suposta introdução na rede da cidade global é a forma de conexão possível com os fluxos e as demandas do capital global na anexação de novos territórios. Lógica do capital que agora vem sendo deslocada espacialmente, pela sua reorientação para países na fronteira da renda mundial, na semiperiferia do sistema global. O processo que ocorre no Rio de Janeiro faz parte de um ajuste espacial global (dirigido ao Sul e ao Oriente geográficos), que completa a difusão dos processos de transnacionalização por meio de um ciclo de produção de eventos projetado nas formas de apropriaçáo dos espaços. O que serve para a montagem dos dispositivos de uma nova grande transformaçáo, ou de novos cercamentos, dando grande atualidade para a obra de Karl Polanyi que descreveu o efeito da radicalização da forma mercantil capitalista (na gênese do capitalismo e na formação do fascismo), sobre o que chamou as mercadorias fictícias, a moeda, o trabalho e a natureza. $\mathrm{O}$ processo da grande transformação e dos cercamentos agora se dá pelas redes e nas cidades, com impacto decisivo nas grandes cidades regiôes, nas megacidades dos países ditos em desenvolvimento, aqueles que representam novas fronteiras para a acumulação mundial (Brasil, China, índia, Indonésia, África do Sul e México).

\section{O Ajuste Espacial Global}

No país da grande mudança geográfica e demográfica do século XX, na direção da urbanizaçẫo acelerada com suas desigualdades e violências intensas, no Brasil, passamos por um novo momento de reconfiguração dos espaços urbanos metropolitanos, com a intensificaçáo de pressóes verticais por reestruturação social e espacial conforme aos termos da agenda globalista. Não vamos, necessariamente, na direção de uma configuração típica de cidade global, mas sim, na de uma forma de interação e inserção mediada de globalidade dentro de uma espacialidade complexa. As formas clássicas de modernização desenvolvimentista, autoritária e conservadora, se davam pela linha da "fuga para diante". Hoje continuamos mimetizando as transfigurações e metamorfoses próprias do mundo do consumo, dos serviços e das ideologias de segurança e urbanização. que resulta na agenda de competiçâo entre as cidades para participarem da promessa de conquista de uma fatia do excedente da riqueza mundial. Na busca da oportunidade de ser o centro virtual do ciclo volátil de atratividade dos business propostos pelos grandes eventos. $\mathrm{Na}$ 
esperança de sua projeção permanente pela via do urbanismo de negócios sustentado na produção imagético-comunicativa.

A estrutura de longa duração das "cidades partidas" é impactada pelo triplo processo: do empreendedorismo urbano, do controle das áreas periféricas e da formação de novos espaços propícios para a produção e o consumo, direcionado para grupos sociais emergentes a partir da nova relação entre crédito pessoal e público. Difundindo a subjetividade e o projeto de uma "nova classe média”, que marca em especial o mundo das redes corporativas globais e, além disso, que faz parte dos contornos dos países chamados BRICS objetivado pelas relaçóes sociais de produção e consumo já presentes nas suas megacidades como São Paulo ou Mumbai. Os processos de ajuste espacial global, quando vistos por dentro do fenômeno urbano tem suas contradiçóes intensificadas nas megacidades. $\mathrm{O}$ que pode ser visto pela periferizaçáo dos centros no Norte do planeta, bem como na reterritorialização da centralidade global em antigas semiperiferias. Nos antigos "segundo" e "terceiro mundo" vemos a urbanização como uma ampliação da fronteira produtiva de sustentação da globalização, no momento mesmo em que ela encontra limites nos países centrais.

\section{A Profusáo de Projetos}

As cidades, como Rio de Janeiro, são cenários de uma experimentação que marca esse momento de transição e retorno ao urbano. A flexão na mundialização através do ajuste espacial global e das megacidades expande a fronteira da acumulação do capital em escala mundial. Nos países de dimensóes continentais e nas megacidades, a pressão das redes corporativas globais se dá dentro do quadro específico das dinâmicas e pressões internas por ingresso no mercado de consumo de massas. A luta distributiva e a lógica especulativa tornam esses territórios (sobre) investidos em todos os aspectos, acentuando os padróes e características dos pacotes econômicos emergenciais. As (des) medidas das alianças entre governos e grandes empresas se legitimam pelas imagens que se difundem apoiando o discurso, "a escrita” de profusão de projetos. Os governos nacionais, regionais e locais vão fabricando projetos, espalhando objetos e simulacros, produtos materiais e virtuais sobre o cenário urbano (com seus teleféricos, museus, torres, shoppings, condomínios).

A agenda pós-industrial poderia ser considerada uma agenda do tipo urbano, indicando claramente a transiçáo contemporânea do projeto nacional de inserção na direção do global (a rede vertical pela corporativa). $\mathrm{O}$ atual projeto produtivo vai na direção do agir pelo poder de mobilizar, realizar e concentrar interesses via empreendedorismo imobiliário (produção do espaço no sentido amplo). Os projetos no Rio de Janeiro, da Vila Olímpica, do Velódromo, do Centro de Mídia, do Parque Aquático, do Estádio são todos bastante concentrados na Zona Oeste, na Barra da Tijuca e no Maracaná. Os projetos contam ainda com a expressão mais ligada à nova tradição de transformação do velho Centro das cidades, aqui pela via de um conjunto de transformações orientadas pelas intervenções urbanísticas ligadas ao chamado Porto Maravilha, encravado e sustentado em terras públicas, com garantias jurídicas especiais, concessóes e empréstimos para

Revista online do Departamento de Arquitetura e Urbanismo da Pontifícia Universidade Católica - 
gerar as parcerias empresariais. Os investimentos nos BRTs, nas três vias expressas e no metrô, ligando a Zona Sul a Barra da Tijuca, consolidam esses recortes territoriais privilegiados.

A política de segurança segue uma geografia orientada pelos interesses articulados no mapa mercantil, com seus traçados definidos pelos eventos. $\mathrm{O}$ peso relativo e diferenciado desse projeto modifica as correlaçóes entre zonas centrais, zonas periferias e zonas de exclusão na cidade, estabelecendo relações entre espaços e interaçóes no que diz respeito aos seus efeitos sobre populações. O que define posições para a qualidade e o conceito de centralidade variável que acompanha as intervençóes no território da parte dita informal da cidade. Passando do projeto favela bairro para o PAC-Urbano em algumas grandes favelas, e agora para a fórmula variada de diversos projetos no âmbito do conceito do Programa Morar Carioca. O balanço desses projetos para a periferia deveria ser registrado nas contradiçóes dessas políticas, como resposta sintomal ao desafio de urbanização das áreas ditas de ocupação irregular. As iniciativas esboçadas nos projetos do Morar Carioca são parte dos dispositivos de respostas parciais (contratadas pela Prefeitura com base em concurso de qualificação realizado pelo IAB) de pequena, média e grande escala na tentativa de integrar a cidade informal como bairro da cidade. Mas esse projeto que vem sendo enfraquecido e contido, embora fosse fator de mobilização crítica de movimentos de moradores lutando por participação, bem como, vinha mobilizando um primeiro esforço de cultura arquitetônica e inovação construtiva, num quasediálogo com a demanda legítima de direito à cidade.

\section{Empreendedorismo Urbano}

O processo de urbanização das favelas vem sendo revertido pela ótica subordinada aos conceitos ligados à área de segurança e ao processo de formalização e privatização das respostas, com fortes campanhas de contenção e controle que ganham respaldo na cultura do medo e na questão das emergências e riscos como deslizamentos e destruição de áreas de reserva. Os efeitos de contenção da verticalização e as remoções promovidas nas áreas de ocupação informal popular são desigualmente distribuídos. A cidade dita formal foi sempre desenvolvida na velha lógica da grilagem garantida por regras fora dos marcos da legalidade constitucional. As classes populares enfrentam conjunturas diferentes entre a remoção, o empate e o reconhecimento. Mas hoje existe um ambiente que justifica intervençôes e legitima apropriaçóes nas áreas informais em direção de novas diretrizes regulatórias, que combinam alianças público-privadas. Para isso, basta ver o financiamento privado das instalaçóes da UPP no Complexo do Alemão.

Por isso, vale parafrasear um velho ditado, para os pobres a lei (o choque de ordem), como vem ocorrendo na repressáo ao comércio ambulante e ao comércio informal nas favelas, assim como, com a aplicação de indenizações de baixo valor e outras medidas ligadas à remoção forçada em nome dos grandes eventos, nos mais variados contextos locais. Tudo por força das necessidades estabelecidas e dos critérios definidos pelos acordos entre tecnocratas e empresas, onde os episódios de remoção de moradores são considerados transtornos "menores", não 
merecendo grande destaque da mídia. As notícias não tratam dos grandes problemas de custos sociais da formalização nas áreas pacificadas na cidade assim como da seleção dos privilegiados e escolhidos para gerir e investir, dos problemas na formação de grupos e consórcios, da fragilidade técnica de opçóes nas políticas de mobilidade, do caráter provisório de açóes e, da pouca transformação nas políticas sociais e de segurança (unificadas de forma provisória sob o rótulo da UPP). Pouco se fala das descaracterizações abandono e improviso com relação aos resultados de concursos e projetos realizados para a região portuária e para o Programa Morar Carioca da Prefeitura do Rio que reúne um conjunto de escritórios de arquitetura com seus projetos.

A formulação das novas políticas de empreendedorismo e marketing urbano, a nova economia em rede e os novos padróes de consumo e reprodução social se interligam através do design, da arquitetura através de certa lógica caótica de produção de objetos, equipamentos e edificaçóes que pretendem ser renovadores e estimuladores de forças de inovação, como ocorreu com a antiga Cidade da Música rebatizada Cidade das Artes. A análise crítica do quadro da agenda pública da cidade, que torna o espaço urbano um objeto ou meio de produção do capital pode ser a oportunidade para desencadear um importante debate no âmbito das opçóes técnicocientíficas e profissionais, pela arquitetura e pelo urbanismo, em especial na Universidade. Mas o processo se acelera na direção do jogo corporativo, no silêncio e na contenção da demanda pela reforma social urbana. A chamada oportunidade para a cidade vai se convertendo num conjunto de processos acelerados de ocupação e apropriação de recursos e privatização de espaços da cidade, onde perde força a agenda da periferia que deve se dirigir para as aspirações do consumo e não da reconfiguração das políticas pela via do habitat.

\section{A Fabricação da Opinião Majoritária}

A agenda dos grandes eventos é conduzida pela lógica instrumental, pelo pragmatismo, pelo improviso, apoiada na retórica nacional de atrair o “espírito animal dos empresários". As políticas de ajuste global se orientam pela necessidade de gerar impacto e resposta por parte dos governantes e das tecnocracias, num ambiente onde vemos certo tipo de fetichismo, com certa ilusão coletiva que náo para de se alimentar da mistura de sentimentos, temores e desejos maximizados pela dimensão dos espetáculos e pela grandeza dos números e valores que fazem explodir o preço do metro quadrado do solo urbano. No meio de um tiroteio e de uma pirotecnia de açóes, projetos, números e prazos, a crítica política é entorpecida pela opinião favorável para a aposta na grande oportunidade para a cidade. A relação entre uma visão da cidade, suas necessidades e os tempos de negociação são atropeladas pelos prazos e exigências de adequação legal, as prioridades são deslocadas e, reafirmados projetos que possam se harmonizar com os efeitos visuais esperados. $\mathrm{O}$ que vai fragmentando, atrasando, protelando e modificando as propostas e as potencialidades urbanísticas e arquitetônicas voltadas para as periferias, esboçadas na primeira fase do PAC Urbano e nas primeiras ações do Morar Carioca. O quadro institucional se dá rompendo com esperanças de participação dos moradores, 
desfazendo supostos consensos de garantias e rompendo acordos técnicos realizados de forma precária com parte das entidades de bairro e de classe. Em processos desse tipo não é novo o silêncio dos vencidos e a aparente unanimidade.

O quadro institucional da coalizão de governo (nos três níveis do sistema federativo) se apoia na mobilidade social de certos grupos e no "quase pleno emprego", com a ampliação da renda e do crédito para setores mais pobres da população que são parte de um momento preciso do ciclo econômico interno, com efeito importante na estrutura urbana pela via do consumo de bens e serviços. Uma circulação de crédito e uma aplicação de parte da renda das famílias em obras de melhoria e reforma nas suas moradias nas periferias, num quadro que se cruza com as políticas distributivas e o aumento do salário mínimo. A periferia está mobilizada e se beneficia de obras públicas intensivas em trabalho durante certos períodos, como em Manguinhos e no Alemão. Mas ao lado disso, os custos de formalização das atividades, o valor dos imóveis e as violações de direitos se ampliam com novas políticas. O quadro político apresenta nuances, mas sem quebrar o quadro favorável para a opinião majoritária, mesmo com o efeito crítico de uma manifestação de oposição eleitoral e de redes sociais, numa relação que se expressou numa faixa próxima de $70 \%$ de votos para o atual prefeito e $28 \%$ para a oposição. No Rio de Janeiro vemos, no início de 2013, uma intensificação dos aparatos informados pela ótica das necessidades impostas pela lógica inexorável na grande imagem das oportunidades abertas, pela participação no espetáculo das cidades que podem aproveitar a visibilidade dada pelos megaeventos. As reflexóes e análises a partir de outras experiências sugerem mais cautela e melhor estruturação dos programas e projetos com base em políticas e planejamento de caráter metropolitano.

\section{Modernidade e Linhas de Fuga}

A modernidade se define pela relação entre os dispositivos técnicos e a dimensão da reprodução social pela estrutura do cotidiano. A produção e o consumo se desdobram pela formação do espaço urbano com suas contradiçóes, fruto da disputa por meios e pela afirmação de certos contextos ou situações, com suas tensões entre repetição e criação, entre mimetismo e obra, entre os horizontes cristalizados e programados e as rupturas e conquistas de direitos. Se para Walter Benjamin os cenários da história têm o alto custo da violência e devem ser lidos pela visão de suas ruínas, e a utopia nasce de escrever a história no contrapelo do progresso pela recuperação da forçada memória dos vencidos onde a revolução tem algo de messiânico; na leitura da modernidade de Henri Lefebvre, a relação entre forma social e a técnica pode abrir caminhos para novos possíveis. $\mathrm{Na}$ escala macro os complexos urbanos que resultam da modernidade devem ser lidos por uma perspectiva crítica metafilosófica, isto é, de reflexão sobre a utopia realista de outros possíveis. A cidade e a técnica estão no centro das questóes que precisam ser abordadas para desvendar as possibilidades de emancipação humana pelas metamorfoses do urbano na grande escala. Monumentos de progresso e cultura técnica podem ser monumentos de barbárie com alto custo humano, mas também podem ser sintomas de movimentos a partir dos quais a mobilização 
política nasce dos efeitos, dos resíduos, capaz de gerar demandas e necessidades que reabrem os horizontes de transformação. Por isso, a leitura à contrapelo dos momentos e movimentos da produção social do espaço é parte da perspectiva metodológica necessária para a crítica da modernidade.

A experiência de atravessar pelo alto, via o teleférico, parte do Complexo do Alemáo no Rio de Janeiro dá uma das medidas da vertigem gerada pela intensificaçáo dos conflitos, conceitos e experiências sobre a construção inacabada e a relação descontínua e oportunista com as zonas trazidas para a nova periferia da megacidade. $\mathrm{Na}$ limitaçáo e falha dos projetos urbanos governamentais, na sua fragmentação e inacabamento vemos o vigor da permanência da autoconstrução da cidade informal popular. Uma leitura do território construído e um olhar de adequação social e técnica apoiada em criatividade estética pode indicar as enormes possibilidades para os desafios da urbanizaçáo em áreas ditas faveladas. As demandas parecem reprimidas e silenciadas diante das falsas necessidades e falsas escolhas formuladas enquanto ordenamento, regulação, repressão e controle. Por isso, vemos uma diversidade de linhas de força, de linhas de fuga, de potencialidades da zona de fronteira, das mediações e articulações entre favela e asfalto, que são atravessadas pelas redes e forças desorganizadas da sociedade, de um lado e, pelas forças de ocupação policial e privatização do território apoiadas pelo Estado.

\section{Projeto Urbano e Comando do Capital}

A arquitetura e o urbanismo são decisivos como disciplinas técnico-científicas, como saberes e práticas que organizam e sustentam processos de produção do espaço. Na sua articulação com a sua dimensão econômica, política, cultural e ambiental são estruturantes de açôes e discursos de construção formal, funcional, estética e institucional com impacto decisivo na definição dos diferentes momentos da conformação da experiência da modernidade. A contemporaneidade e os modos de produção e consumo possuem expressão material e simbólica intensa e cristalizada do ponto de vista antropológico, temporal e espacial, que impulsionam as dinâmicas de territorialização, desterritorialização e reterritorialização que cristalizam as configuraçôes históricas na geografia das formações econômicos sociais.

Na modernidade os modos de reprodução social e a acumulação do capital se materializam na construção e reprodução do espaço geográfico intensificado e ampliado pelas metamorfoses do espaço urbano difuso. As metrópoles da semiperiferia capitalista, como o Rio de Janeiro, parecem estar explodindo por força da combinação dos processos de globalização, reestruturação e constituição do meio geográfico marcado pelo domínio das tecnologias, da informação e da comunicação. A lógica financeira abstrata, os processos de consumo de massas, a passagem para o primado dos serviços, a privatização do público, a precarização do trabalho, a criminalização das populaçóes e territórios periféricos, a compressão técnica e produtiva sob o comando de redes corporativas globais. As novas políticas de controle e segurança e a espetacularização midiática da produção 
cultural geram um novo regime de transformação das fronteiras, territórios e cidades, apoiado no ciclo de longa duração da revolução urbana no plano mundial. As novas geografias

contemporâneas definem recomposiçóes espaciais e temporais que se traduzem em novas divisões sociais marcadas pelo choque da aproximação acelerada entre o local e o global, que se intensifica com a adesão dos agentes do Estado ao processo de (des) nacionalização, numa transição que gera novos regimes de fronteira, novos contextos institucionais e embates no plano dos direitos e do acesso aos bens e serviços e aos processos de decisão que são alienados nos padrôes de gestão tecnocráticos e na força dos blocos sociais relacionados às dinâmicas de transnacionalização.

No quadro descrito nesse artigo podemos compreender o alcance da reflexão espacial com foco na arquitetura e no urbanismo como expressáo de escrita organizadora, produtora $\mathrm{e}$ criadora de espaços. Enquanto desenho das formaçóes sociais urbanas deve ser vista como uma tecnologia social que serve de suporte de vida. Arquitetura é arte, tecnologia, poder de sugerir, propiciar, projetar os modos de ocupar, usar e aprimorar o espaço habitável. A territorialização e seus usos enquanto olhar educado e informado pela arquitetura se estende através do urbanismo. Uma disciplina técnico-científica que articula o social, o humano, o biológico, o físico e o químico, manejando os materiais e os valores propiciadores de movimentos, de distribuição, circulação e mobilidade das populaçôes no espaço. É um suporte decisivo de criação e conhecimento, meio de produção do tempo instituído, um suporte para o visível e o invisível, que sobredetermina as dimensóes do poder urbano.
No que ele se traduz em esferas e espaços nas várias escalas de produção, de construções com diferença quanto aos pesos e significados simbólicos. Nas formas que vão do banal ao monumental ou nas diferentes funções de moradia, do lazer, quer na esfera pública quer na esfera privada.

\section{O Desafio}

A nossa reflexáo procura destacar a leitura da conjuntura urbana enquanto dimensão de disputa institucional e da orientação das políticas urbanas num quadro estrutural marcado pela reestruturação mundial do capital, através de sua implicação com a produção e as contradiçóes no espaço. Para o que tomamos por objeto a cidade do Rio de Janeiro como um espaço intensificado da experimentaçáo de um tipo de utilitarismo, da aplicação de um pragmatismo na estratégia do governo do território, com certa biopolítica de controle social e espacial.

A relação entre forma, função e estrutura está no centro da abordagem arquitetônica da análise do fenômeno urbano. $\mathrm{O}$ modo de ver a cidade é guiado pela experiência do ator informado que é limitado pelos condicionamentos e possibilidades criativas e construtivas de um dado período histórico. Numa dada situação ou correlação de forças os conflitos se dão em meio a uma dialética que se abre num momento político determinado, ou seja, numa conjuntura cuja leitura crítica pode ser propiciadora da construçáo de outros possíveis nos modos de vida coletivos. Uma teoria social crítica do espaço deve ser apoiada numa pesquisa em que a dimensão fenomenológica, a objetivação e a subjetivação dos processos existenciais 
coletivos, onde o vivido é captado por uma metodologia que reconstrua os momentos, como a conjuntura de reestruturação urbana via produção do espaço para a atraçáo do capital utilizando a lógica do global para ativar todo o processo de reprodução ampliada.

Através das conjunturas e dos seus ritmos e intensidades, podemos medir os efeitos das práticas espaciais pela via da observação das disciplinas, como a geografia, o planejamento urbano e a arquitetura, que dão destaque para o peso do espaço construído do que se escreve pelo desenho dos recortes do território usado, do ocupado, do construído. Nessa ótica o olhar informado pelo urbanismo como dimensão teórica e prática do conhecimento dos fenômenos e processos da Cidade, leva em conta as forças que circulam e se distribuem a riqueza, a presença dos objetos e dos agentes, medidos pela relação entre sistemas de ação e sistemas de objetos, entre fixos e fluxos que configuram relaçóes sociais de produção e as dimensóes ecológicas próprias ao urbano.

As esferas e configuraçóes do urbano são vistas enquanto resultado da atividade humana, enquanto espacialidades que condensam e são atravessadas por graus e qualidades distintas de temporalidades. A sociedade é atravessada pela reflexividade (conhecimento elaborado com efeito sobre a ação), a partir do território organizado e da sua fragmentação derivada dos ciclos e do conflito resultante do agir humano individual e coletivo. A arquitetura inclui entre as suas exigências a capacidade de leitura dos territórios usados, um modo de ver as muitas tensóes, aberturas e as potencialidades que permite ampliar a experiência da ecologia humana. Permite uma práxis sobre o habitar, na expressão funcional, formal e estrutural que produz, distribui e dispóem os objetos, as construções, os equipamentos e outros fixos que permitem o bem viver localizado, com todas as suas consequências de design do social. Daí sua relevância para o diálogo entre as várias modalidades de saber técnico e científico que nos permite atuar econômica, política e esteticamente sobre as reconfigurações e materialização dos modos de vida e em especial das artes de desenhar e projetar o uso dos espaços, com destaque para o espaço comum, social e público com o qual lida o urbanismo enquanto dimensão estratégica das práticas espaciais, da programação e do planejamento para lidar com as demandas de concretização do acesso aos direitos na sua relação com os usos do território.

\section{A Escrita}

Uma cidade se escreve pelos traçados que se cristalizam nos objetos, nas práticas e nas imagens que habitam a cena contemporânea que se materializa diante dos seus habitantes. A megacidade explode na sua impossibilidade de se organizar desde uma centralidade, desde uma linha de força dominante. A diversidade de agendas e temporalidades se traduz nas espacialidades que desde muitos ritmos faz uma escrita, pelos corpos e pelas mentes. O tempo histórico se cristaliza na geografia, nos territórios definidos pelos seus usos. O que podemos observar nos lugares onde se registram os trajetos e a incidência das práticas espacializadas dos habitantes da Cidade. Cabe trabalhar analiticamente o fenômeno urbano desde uma teoria da ação, o que implica em desvendar 
intenções, desvendando os sentidos que lhe são dados pela combinação entre verticalidade e horizontalidade, entre as forças da dominação e as práticas diárias dos habitantes. Como construir o mapa desses traçados sem partir de uma conjuntura concreta, de um momento histórico preciso como condição de lidar com a longa duração? O momento da mudança define as condições de reprodução da estrutura (longa duração) que só existe nas suas atualizações e mudanças.

O imperceptível, o repetitivo e a materialidade do cotidiano podem ser lidos pelas forças da descontinuidade. Perguntar sobre a nova conjuntura do Rio de Janeiro nos permite falar das metamorfoses e da duração da forma periférica, da cidade informal e popular parte da megacidade (plural desigual e diversa). A centralidade da periferia como problema e solução para o desafio colocado pelo retorno do espaço como uma manifestação decisiva da era das redes transnacionais, da lógica financeira, do poder cibernético e da revolução promovida pelas NTIC. Trabalhar sobre a relação entre as agendas estratégicas contemporâneas para a produção social do espaço urbano, sobre a conjuntura de implantação de um paradigma hegemônico, nas suas traduçóes e adaptações para uma megacidade determinada, é o como caminho para pensar a estrutura em movimento. Trabalhar sobre a forma, a função, a duração, a intensidade para desvendar uma escrita, os discursos, as narrativas e as práticas que constituem os usos e as apropriações do território exige a construção de um esquema de leitura, um mapa das contradiçôes do movimento das novas centralidades.
A análise da situação se dá pela identificação das correlações, a linhas de força e as expressóes fenomênicas das temporalidades, pelas espacialidades. Onde os processos de formação dos projetos, no interior das políticas, singularizam as experiências e definem os contornos do conhecimento das dinâmicas espaciais. Onde as lutas entre centro e periferia se travam na reprodução ampliada do social e na produção do cotidiano, por deslocamentos no mundo da vida, nas práticas, nos ritos, nas imagens e nos mitos que habitam a vida de cada cidade, que como o Rio de Janeiro estão no olho do furacão. Megacidades atravessadas pela dimensão explosiva do urbano na contemporaneidade. Esse método pode ser aplicado ao entendimento do que se passa na reestruturação do espaço urbano condicionado pela crise e transição do regime global de acumulação na relação entre as suas diferentes espacialidades (globais nacionais e locais).

\section{O Modo de Governar a Cidade}

No Rio Janeiro a conjuntura passa a estar marcada pela existência de uma arquitetura de resultados, de um urbanismo de segregação funcional e produtiva. A produção de políticas do poder local é marcada por um novo regime de governo voltado para uma combinação de clientelismo eleitoral, de um lado, e de empreendedorismo urbano de outro, seu cruzamento na agenda nacional gerou dois blocos de forças e tendências que dominam a cena pública e se combinam de forma paradoxal, um bloco de forças centrado na relação entre empreendedorismo global e fisiologismo nacional e um bloco de forças que 
afirma, sem romper com o primeiro no plano da economia e da política urbana, dentro de uma visão mais moralizante e antipolítica. $\mathrm{O}$ processo e as tendências da conjuntura fortalecem a reestruturação do espaço para o capital, por força da nova institucionalidade e das medidas de exceção e emergência voltadas para tornar os territórios lugares de capazes de incorporar objetos, monumentos, edificaçóes e equipamentos capazes de gerar negócios, entendidos como uma condição primeira para a realização da vida social. Vimos que é na análise de situação que podemos visualizar os processos de mudança de modo a poder demarcar as estratégias espaciais molares e moleculares dos diferentes grupos sociais na cidade. $\mathrm{O}$ cotidiano é fortemente modificado em tempos de reestruturação mundializada do capitalismo, realizada através da incorporação crescente de lógicas territoriais, de apropriação e produção social do espaço como dimensão reprodutiva do capital. No século XXI vivemos sob o impacto da lógica abstrata da valorização do capital que acelera a passagem da era industrial para a era urbana. A mundialização em arquipélago é uma das metáforas que descrevem as condições de implosão e transformação das metrópoles e de formação dos sistemas de redes de cidades, duas tendências imanentes ao movimento da fragmentação e da difusão do espaço na forma da cidade região e da megacidade. Os processos pós-metropolitanos se apresentam como um conjunto de espacialidades, novas relaçóes e processos condicionados pelo ciclo global do capital.

A leitura dos processos sociais projetados enquanto práticas e relaçóes de apropriaçáo, distribuição e presença no espaço exigem a mobilização de um conjunto de saberes. $\mathrm{Na}$ confluência das relaçôes internacionais, da geografia e da arquitetura a análise das dinâmicas urbanas contemporâneas devem se somar para apreender as tendências e identificar as formas sócias e de poder que derivam das práticas e lutas no espaço urbano, em particular nas megacidades dos países da semiperiferia global. O convite de Prumo nos levou a buscar a trama, o teatro das operaçóes definidas pelas agendas políticas, pelas táticas que constituem a situação (conjuntura e espetáculo) que singulariza os ritmos, os estilos e os eventos presentes na cidade do Rio de Janeiro.

$\mathrm{Na}$ tensão entre a fenomenologia da globalização com fragmentaçáo e das estratégias de controle e disciplina para a acumulação capitalista global, os ritmos e intensidades ampliados pelas inúmeras intervenções, programas e projetos fazem da cidade do Rio de Janeiro um objeto do desejo, onde um discurso se traduz em formas precisas de ação nos termos do novo espírito do capitalismo. $\mathrm{O}$ que se dá por meio de projetos e ações pragmáticas e instrumentais, que partindo de uma unidade discursiva se implica e se traduz em práticas de produção imanente do espaço com a fabricação de objetos e signos mercantis. O que vem acentuando o desenvolvimento desigual e bloqueando um avanço no horizonte da consistência em matéria de qualidade do desenvolvimento urbano na Cidade.

$\mathrm{Na}$ era histórica conduzida pelo capital financeiro através da relação entre credor e devedor, pela dívida pública, pelo investimento governamental. Os tributos e o consumo se articulam com a mesma estrutura que converge para o ganho com a construçáo imobiliária, a produção do espaço urbano conduzida para o alongamento combinado

Revista online do Departamento de Arquitetura e Urbanismo da Pontifícia Universidade Católica - 
das bases materiais e da reprodução no tempo do ciclo do capital. As técnicas relacionadas ao sistema de crédito se projetam na coordenação do ciclo temporal e das dinâmicas espaciais, pela via da privatização do público e pela apropriação do que é comum (natureza, trabalho e linguagem). $\mathrm{O}$ modo de reprodução do capital se articula no espaço das redes de informaçáo e comunicação e das redes de circulação de bens e mercadorias pela estrutura do cotidiano e pela vida urbana, as expressóes e intervençôes urbanísticas e arquitetônicas se relacionam com as necessidades de controle social e rentabilidade, segurança e atratividade para o investimento estão no centro das lógicas e tecnologias que comandam os aparelhos de governo. As disputas entre as práticas coletivas de sobrevivência e ocupação do espaço urbano acompanham e pressionam o espaço da cidade formal ao serviço do capital, onde uma lógica de apropriação para a valorização exige a flexibilidade do espaço, dos corpos e das mentes para definir os territórios segundo a apropriação para fins de rentabilidade.

\section{A Política de Atraçáo, Funçáo e Produçáo do Espaço para o Capital}

No século XXI entramos na era urbana acelerada pelas mudanças tecnológicas e pela mundialização do capital, contexto que gerou o que denominamos de novas espacialidades. No período atual a conjuntura urbana é marcada por intensidades empiricamente verificadas na produção social do espaço flexível para o capital financeirizado. $\mathrm{O}$ mercado de terras, a indústria de construçáo, as obras públicas e o consumo privado se entrelaçam pela via dos sistemas de crédito e endividamento, acompanhando o processo de deslocamento para a produçáo imaterialcomunicativa e para a industrialização dos serviços. No âmbito da sociedade a cidade substitui a fábrica, onde a luta pelo espaço e as práticas cotidianas se relacionam com a busca antecipada do endividamento de empresas e indivíduos. $\mathrm{O}$ processo especulativo que incide sobre o mercado de terras e os imóveis é expressão do poder da máquina de endividamento. A inflação é o resultado das disputas distributivas que expressam a pressão resultante das forças $\mathrm{da}$ acumulação intensificada.

A produção do espaço atrativo e flexível na cidade se apoia na continuidade das mesmas políticas construtivas e de anexação de novos espaços, sustentada pelos mesmos registros de mimetismo em matéria de arquitetura monumental. As administraçôes locais e os Estados Nacionais apoiam esse modelo de políticas atrativas para o capital, através de sua panóplia de intervençóes tópicas em matéria de tecnologias de poder, de comunicação e de produção de infraestrutura urbana e equipamentos. As divisôes dos espaços em territórios se dão em conformidade com uma divisão vantajosa para os consórcios bancários e construtivos. No Rio de Janeiro se repete o padrão de articulação entre a institucionalidade e espetáculo. A planificaçáo da ação governamental é o resultado da soma de projetos orientados pelo paradigma hegemônico (pelas regras favoráveis aos monopólios, marcas e registros de propriedade intelectual e compra de serviços), com a adequação das normas jurídicas que delimitam as condições de exploração dos espetáculos e a venda de bens e serviços no território. A transmissão de imagens nas redes de comunicação opera ao lado

Revista online do Departamento de Arquitetura e Urbanismo da Pontifícia Universidade Católica - 
do pagamento e da compra de máquinas, de sistemas, de programas e de instrumentos que servem de meios de produção e consumo conforme as delimitaçóes e contratos internacionais da FIFA e do COI.

As alianças entre os grupos sociais e as forças políticas dominantes estão voltadas para explorar as vantagens construídas e as ilusões coletivas da agenda dos grandes eventos. As cidades que melhor aproveitam as agendas de atração de eventos internacionais são aquelas que possuem uma melhor programação e estruturação do seu planejamento urbano estabelecido ex-ante. As cidades que se adaptam e improvisam em matéria de política e projetos tendem a gerar custos maiores com efeitos crescentes em matéria de desigualdade sócio-espacial e de endividamento público e privado. Prevalece uma programação econômica condicionada pelas regras proprietárias de captura da mais-valia (social) territorial, com um efeito especulativo e rentista desencadeado pelos grandes eventos globais.

No Rio de janeiro o movimento das formas globais vai atropelando os tempos e ritmos da construção de infraestruturas. As forças do capital tentam pilotar a reestruturação urbana, buscando adequação relativa aos termos da programação contratada no plano internacional gerando uma verdadeira contrarreforma na Cidade do Rio. O planejamento estratégico movido pelo marketing urbano se relaciona com o pragmatismo utilitarista da construção de inúmeras reservas de mercado, que se projetam em recortes espaciais, com o monopólio de atividades e outros privilégios concedidos a grupos nacionais e transnacionais, que passam a ter legitimidade por legislação especial, pelas formas jurídicas de exceção e pelas políticas de controle e segurança.

Os deslocamentos imateriais e as construções ideológicas e simbólicas são parte da disputa semiótica. O que encobre o fato de que as transformaçóes são intensificadoras do mesmo, o eterno retorno em matéria de transporte, em matéria de distribuição espacial de benefícios, com um reforço de práticas da gentrificação. O que suspende a perspectiva de estabelecer um tipo de planejamento e de modo de governar conforme expectativas inscritas na Constituição Brasileira e no Estatuto da Cidade.

\section{Conclusão}

A cidade do Rio de Janeiro é objeto de um conjunto amplo de ações que combinam a dimensão simbólica e a dimensão arquitetônica de projetos urbanos, que acentuam suas características de negociações de porteira fechada, de acordos de cúpula e de criação de legislação especial. A velocidade com que se modificam prazos, contratos e, até mesmo, os traçados de projetos, se relaciona com o caráter improvisado e imediatista de certas (in) decisóes, que se refletem com mais intensidade na definição fetichista voltada para os grandes objetos, como as torres que se pretende colocar no "Porto Maravilha". Os impactos sociais como as remoções são modificados a todo tempo, sem margem de negociação ou de atendimento adequado das populaçóes e setores da população afetados como na área do Maracanã. Os movimentos sociais e as denúncias de custos das obras, inadequação de traçados e de opçóes, como no caso do metrô e de outras áreas definidas para a passagem da Transolímpica, vão se acumulando. 
Nesse quadro, todas as implicaçóes das divisóes do território e das concessóes de porteira fechada criam enclaves. Nas áreas escolhidas são montados os canteiros de produção de espaços de valorização do capital em prol das grandes empreiteiras. As políticas, programas e projetos beneficiam os agentes privados nacionais, os agentes internacionais, algumas famílias de renome e personagens que colocam suas placas nos vários canteiros que se espalham pela cidade. Os seres empresariais de vocação "animal” fazem parte do novo espírito capitalista de destruição criativa do espaço urbano, refazendo a cidade como arquipélago, por pedaços e por traçados dentro de um planejamento de ocupação.

A economia da circulação e da comunicação e as políticas de mobilidade acentuam as tendências de polarização e fragmentação que desarticulam a cidade, sem aproveitar as possibilidades para qualificar o território usado, construído com suas densidades e proximidades, sem enfatizar e aproveitar de maneira mais consistente o espaço construído. Essas observações longe de ser resultado de uma avaliação radical de alguns grupos políticos faz parte de um discurso corrente da representação nacional dos arquitetos. Nitidamente estamos perdendo a capacidade de retomar a relação entre os instrumentos de planejamento e participaçáo com controle social previstos no Estatuto da Cidade. Fica distante a perspectiva de uma visão do espaço urbanometropolitano que lida com estratégias de proximidade. Estreitando as possibilidades de uma melhor qualificação da cidade realmente existente, para o adensamento em matéria de construção de equipamentos na relação com a leitura da cidade que leve em conta a necessidade de uma centralidade da periferia.

\section{Referências Bibliográficas}

COCCO, Giuseppe; SARITA, Albagli (Org). Revolução 2.0: e a crise do capitalismo global. Rio de Janeiro: Garamond, 2012.

DEBORD, Guy. A sociedade do espetáculo. Comentários sobre a sociedade do espetáculo. Rio de Janeiro: Contraponto, 1997.

HARVEY, David. A produção capitalista do espaço. São Paulo: Annablume, 2005.

HESS, Remi; DEULCEUX, Sandrine. Henri Lefebvre. Vie. Oeuvre. Concepts. Paris: Ellipses, 2009.

JAUREGUI, Jorge. Estrategias de articulacíon urbana. Buenos Aires: Nobuko, 2012.

LEFEBVRE, Henri. La production de l'espace. 4 ed. Paris: Anthropos, 2000.

MATTELART, Armand. La globalisation de la surveillance. Aux origines de l'ordre sécuritaire. Paris: LaDécouverte/Poche, 2008.

PERULLI, Paolo. Visões da cidade: as formas do mundo espacial. São Paulo: Editora Senac, 2012.

POLANYI, Karl. A grande transformação. As origens da nossa época. 2. ed. Rio de Janeiro: Campus, 2000.

RIBEIRO, Ana Clara Torres. Por uma sociologia do presente: ação, técnica e espaço. Rio de Janeiro: Anpur-Letra Capital, 2012.

SANTOS, Milton. Espaço e método. 5. ed. São Paulo: Edusp, 2008.

SASSEN, Saskia. Critique de l'État. Territoire, autorité et droits de l'époque medieval à nos jours. Paris: Le Monde Diplomatique-Demópolis, 2009. 
SOJA, Edward. Geografia pós-modernas: a reafirmação do espaço na teoria social crítica. Rio de Janeiro: Jorge Zahar Ed., 1993. 